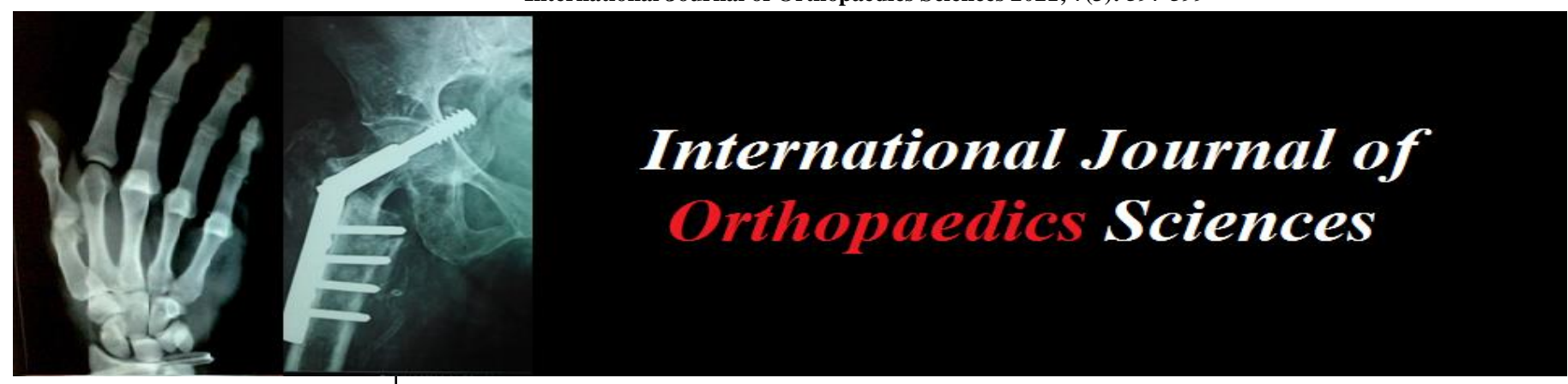

E-ISSN: 2395-1958

P-ISSN: 2706-6630

IJOS 2021; 7(3): 597-599

(C) 2021 IJOS

www.orthopaper.com

Received: 16-05-2021

Accepted: 18-06-2021

\section{Madhusudan S Khomp}

Department of Orthopaedics,

HOSMAT Hospital, Magrath

Road, Bengaluru, Karnataka,

India

\section{Prathap US}

Department of Orthopaedics, HOSMAT Hospital, Magrath Road, Bengaluru, Karnataka, India

Kannan Karupaiah Kumar Department of Orthopaedics, HOSMAT Hospital, Magrath Road, Bengaluru, Karnataka, India

\section{Punith N}

Department of Orthopaedics, HOSMAT Hospital, Magrath Road, Bengaluru, Karnataka, India
Corresponding Author: Prathap US

Department of Orthopaedics, HOSMAT Hospital, Magrath Road, Bengaluru, Karnataka, India

\section{Management and outcome of subungual glomus tumours: A series of 21 cases}

\author{
Madhusudan S Khompi, Prathap US, Kannan Karupaiah Kumar and \\ Punith N
}

DOI: https://doi.org/10.22271/ortho.2021.v7.i3i.2808

\section{Abstract}

Introduction: Glomus Tumour are vascular neoplasm that arise from glomus body. They are benign hamartomas most commonly occurring at subungual region of digits. They can cause recurrent episodes of intense lancinating pain and disability. Patients often undergo undiagnosed or misdiagnosed for many years because the tumours are small. The purpose of our study was to assess pain relief and recurrence rate after complete excision of tumour.

Material and Methods: Twenty one patients were included in the study. All cases were assessed clinically and on MRI. Glomus tumour excision was done under microscope and the diagnosis was confirmed post-operatively by HPE. Pre- and Post-operative VAS scores were compared to evaluate the symptomatic outcome. Recurrence was assessed by recurrence of pain and MRI changes.

Results: Out of 21 patients 18 were females and 3 were males. The mean age was 35 years. All patients showed dramatic relief of pain after surgical excision. Early diagnosis and surgical excision decreases patient's sufferings from severe pain and disability. The average improvement in VAS score was from 7.952 (pre-op) to 1.048 (post-op). No recurrence observed at 24 months follow-up.

Conclusion: Glomus tumour is a rare disease, one should have a high index of suspicion for Glomus tumour in intractable chronic fingertip pain. Excision of Glomus tumour under microscope allows better tissue clearance and hence low recurrence rate.

Keywords: glomus tumour, subungual

\section{Introduction}

Glomus tumours are rare benign hamartoma of vascular origin, arising from Glomus body [1] Glomus body is a contractile neuromyoarterial receptor which is innervated, coiled, arteriovenous dermal shunt that normally regulates skin temperature by regulating blood flow in the cutaneous microvasculature. They are highly concentrated in the tips of the digits, particularly in the subungual area ${ }^{[2]}$. Glomus tumours account for $1 \%$ to $5 \%$ of all soft tissue tumours of the hand ${ }^{[4]}$. Histologically, glomus is a specialized vascular anastomotic complex surrounded by nerve elements ${ }^{[5]}$. A glomus body is composed of an afferent arteriole, an anastomotic Suquet-Hoyer canal, an efferent venule, actin containing glomus cells surrounding the canals, the intraglomerular reticulum, and a capsular portion ${ }^{6}$. The common clinical presentation is a painful, tender nodule.

Some diagnostic tests for glomus tumour include the Love's pin test, Hildreth's test and the cold sensitivity test ${ }^{[4]}$.

Pain at the fingertip was the common complaint in all reported cases ${ }^{[7]}$. Because of the rarity and small size of the tumour, the diagnosis is often missed ${ }^{[8]}$. The Love's test described in 1944 by Love ${ }^{[9]}$, which consist of applying pressure over the painful area with the head of a straight pin, is very useful for precisely locating the site of the lesion. Hildreth (1970) described an ischaemia for the diagnosis of glomus tumours ${ }^{[10]}$. It is positive if there is a reduction in pain and tenderness on exsanguination and ischaemia of the affected part. Hildreth's test is sensitive (92\%) and specific (91\%) for glomus tumour ${ }^{[10]}$. The dorsal bone erosion of distal phalanx in the case of subungual tumours is reported only in $22 \%$ of cases ${ }^{[11]}$. Magnetic resonance imaging (MRI) is used in some cases to support clinical diagnosis. 


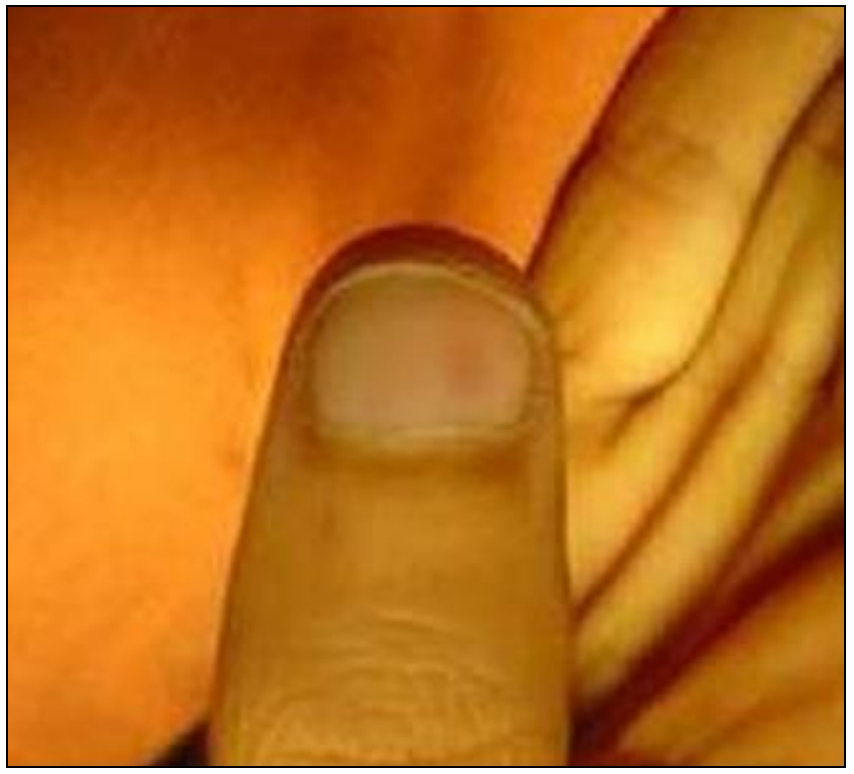

Fig 1: Glomus tumour of thumb.

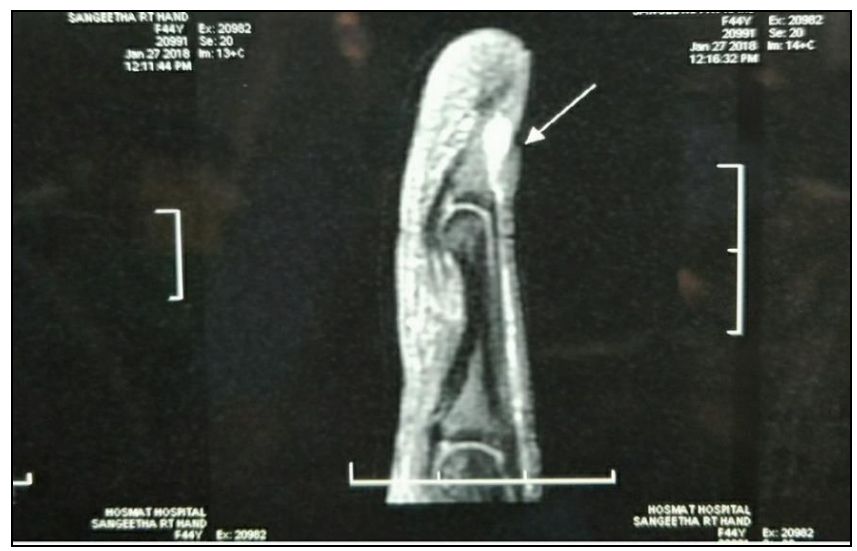

Fig 2: MRI showing the location of the tumour.

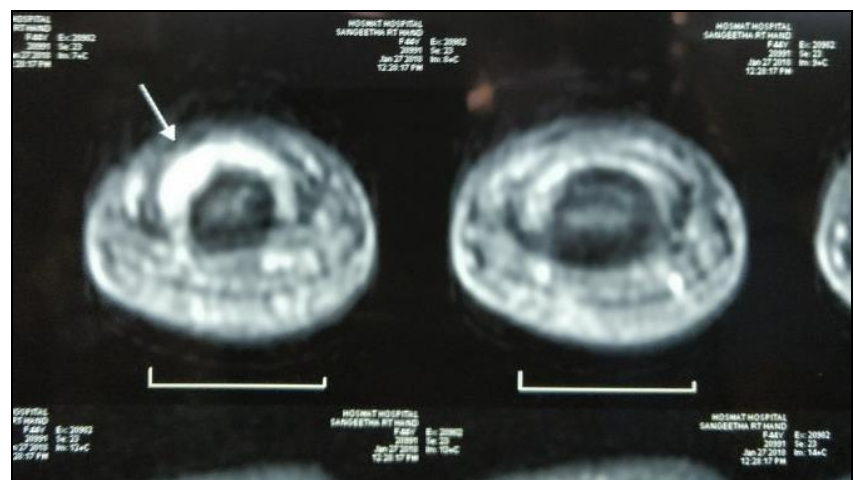

Fig 3: MRI showing the location of the tumour.

Surgical excision is the only known treatment option for subungual glomus tumor ${ }^{12}$. The objective of the study was to assess pain relief and recurrence rate after complete excision of the tumour.

\section{Materials and Methods}

21 patients who underwent glomus tumour excision under microscope were assessed retrospectively between 2015 and 2019. All cases were assessed clinically and on MRI. The diagnosis was confirmed post-operatively by HPE. Pre- and Post-operative VAS scores were compared to evaluate the symptomatic outcome. Recurrence was assessed by recurrence of pain and MRI changes. All patients were followed-up for a period of 2 years.

\section{Surgical Technique}

Surgery is performed under tourniquet control. Rubber band of surgical gloves is used as tourniquet placed at base of finger with local anaesthetic digital block. The standard approach is direct trans-ungual excision, in which the nail plate is removed and nail bed is incised longitudinally with a number 15 blade directly over the area of the tumour. The tumour is then excised completely under microscope.

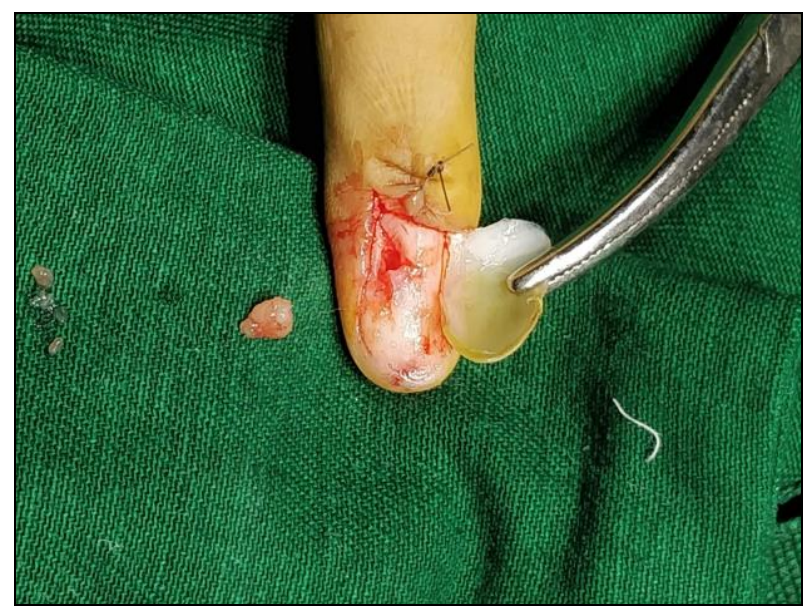

Fig 4: Intraoperative view of glomus tumour excision.

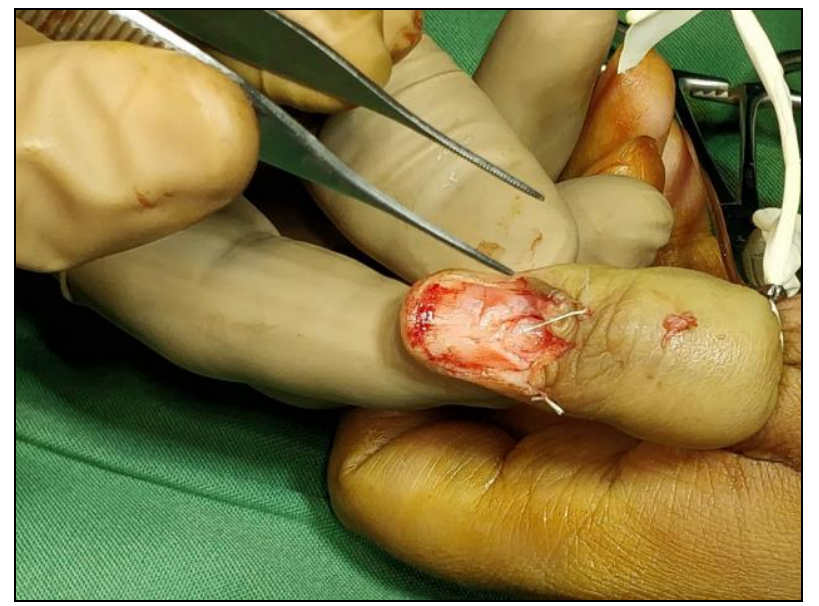

Fig 5: Nailbed after excision of the tumour.

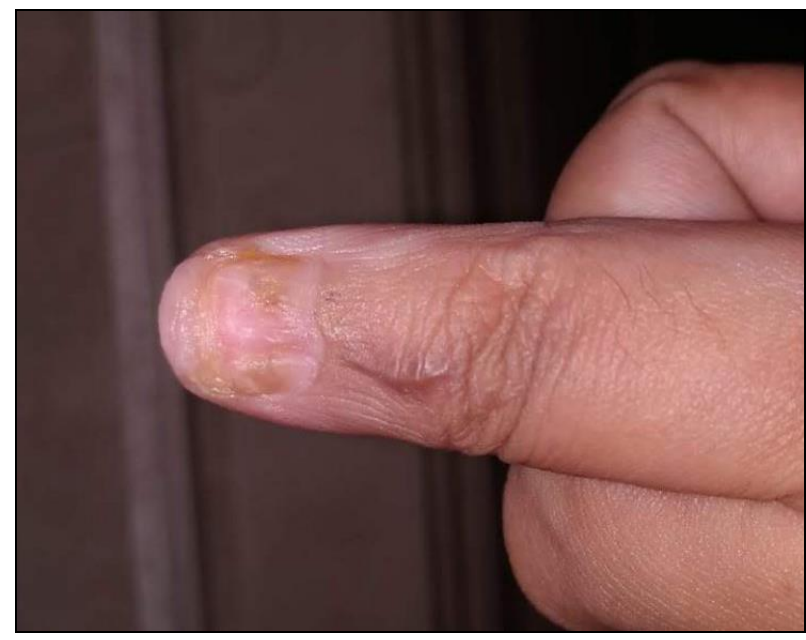

Fig 6: Postop followup after 3 months.

\section{Results}

The study included 21 patients with glomus tumours of which 18 were females and 3 were males. The average age of the patients was 35.5 years. All the tumours were less than $4 \mathrm{~mm}$ 
in diameter except for one patient who had an $8 \mathrm{~mm}$ lesion. All patients had complete relief of pain after surgical excision. None of the patients had recurrence of tumour or complications including postoperative nail deformity in follow up period. All of them returned to their preoperative occupation and regained full function of the hand.

Table 1: Distribution of the patient by sex

\begin{tabular}{|c|c|}
\hline Sex & Numbers \\
\hline Male & 3 \\
\hline Female & 18 \\
\hline
\end{tabular}

Table 2: Distribution of the patient by location of the tumour

\begin{tabular}{|c|c|}
\hline Location & Number \\
\hline Thumb & 7 \\
\hline Ring Finger & 6 \\
\hline Index Finger & 5 \\
\hline Middle Finger & 3 \\
\hline Total & 21 \\
\hline
\end{tabular}

Table 3: Improvement in VAS Score.

\begin{tabular}{|c|c|}
\hline VAS Score & Average \\
\hline Preop & 7.952 \\
\hline Postop & 1.048 \\
\hline
\end{tabular}

\section{Discussion}

Glomus tumour are rare benign hamartoma arising from glomus body. It accounts for 1 to $5 \%$ of soft tissue tumours of the hand and $75 \%$ are subungual. They are more common in women particularly in middle age. In our study mean age of the patients was 35.5 years and $85 \%$ of the patients were female.

Table 4: Comparison of sex ratio in similar studies.

\begin{tabular}{|c|c|c|}
\hline Study & Sex Ratio (M:F) & Total \\
\hline Current study $^{[12]}$ & $3: 18$ & 21 \\
\hline Hamdi $^{[1]}$ & $3: 5$ & 8 \\
\hline Jawalkar $^{[3]}$ & $3: 9$ & 12 \\
\hline
\end{tabular}

All of the glomus tumours were found on the distal part of the finger, beneath the nail plate. Thumb was affected more.

Table 5: Comparison of location of tumour in similar studies.

\begin{tabular}{|c|c|c|c|c|c|c|}
\hline Study & $\begin{array}{c}\text { Thumb } \\
\text { finger }\end{array}$ & $\begin{array}{c}\text { Index } \\
\text { finger }\end{array}$ & $\begin{array}{c}\text { Middle } \\
\text { finger }\end{array}$ & $\begin{array}{c}\text { Ring } \\
\text { finger }\end{array}$ & $\begin{array}{c}\text { Little } \\
\text { finger }\end{array}$ & Total \\
\hline Current study & 7 & 5 & 3 & 6 & 0 & 21 \\
\hline Hamdi $^{[12]}$ & 3 & 1 & 2 & 1 & 1 & 8 \\
\hline Jawalkar $^{[3]}$ & 3 & 5 & 3 & 1 & 0 & 12 \\
\hline
\end{tabular}

A patient of glomus tumour presents with classical triad of excruciating pain, point tenderness and increased sensitivity to cold. Clinical tests, such as Love's test, Hildreth's test, cold sensitivity test may aid diagnosis. Magnetic resonance imaging (MRI) is used in some cases to support clinical diagnosis. Conventionally the glomus tumours show increased signal intensity on $\mathrm{T} 2$ weighed images, especially after gadolinium injection. The value of MRI is in the diagnosis of recurrent glomus tumours, with the persistence of postoperative pain ${ }^{[13]}$. Total surgical excision is the cure for glomus tumour. All excisions were done under microscope which allowed better clearance of tumour. It results in dramatic pain relief in immediate postop period. One patient operated in another institute presented to us with recurrence, after excision there was no recurrence at 2 year follow-up.

\section{Conclusion}

Glomus tumours are rare accounting for only $1-5 \%$ of all soft tissue tumours of hand. Most commonly presents in females in subungual region. One should have a high index of suspicion for glomus tumour in intractable chronic fingertip pain. The only treatment of glomus tumour is surgical excision. Excision of Glomus tumour under microscope allows better tissue clearance and hence low recurrence rate.

\section{References}

1. Mc Dermott EM, Weiss AP. Glomus tumour. J Hand Surg Am 2006;31:1397-400.

2. Tomak Y, Akcay Y, Dabak N, Eroglu L. Subungual glomus tumours of the hand: diagnosis and treatment of 14 cases. Scand J Plast Reconstr Surg Hand Surg 2003;37:121-4.

3. Jawalkar H, Maryada VR, Brahmajoshyula V, Kotha GKV. Subungual glomus tumour of hand: Treated by transungual excision. Indian J Orthop 2015;49(4):403407.

4. Tuncali D, Yilmaz AC, Terzioglu A, et al. Multiple occurrences of different histologic types of the glomus tumor. J Hand Surg 2005;30A:161-164.

5. Gombos Z, Zhang PJ. Glomus tumor. Arch Pathol Lab Med 2008;132:1448-1452.

6. Drape JL, Idy-Peretti I, Goettmann S, et al. Subungal glomus tumors: evaluation with MR imaging. Radiology 1995; 195:507-515.

7. Nazerani S, Motamedi MH, Keramati MR. Diagnosis management of glomus tumors of the hand. Tech Hand Up Extrem Surg 2010;14(1):8-13

8. Sun BG, Yun-tao W, Jia-zhen L. Glomus tumours of the hand and foot. Int Orthop 1996;20(6):339-341

9. Love JG. Glomus tumors: diagnosis and treatment. Proc Staff Meet Mayo Clin 1944;19:113-116.

10. Giele H. Hildreth's test is a reliable clinical sign for the diagnosis of glomus tumor. J Hand Surg $[\mathrm{Br}]$ 2002;27:157-158.

11. Vandenberghe L, De Smet L. Subungual glomus tumours: a technical tip towards diagnosis on plain radiographs. Acta Orthop Belg 2010;76(3):396-397.

12. Mohamed Faouzi Hamdi. Glomus tumour of fingertip: report of eight cases and literature review: Musculoskelet Surg 2011;95:237-240.

13. Theumann NH, Goettmann S, Le Viet D, Resnick D, Chung CB, Bittoun J, et al. Recurrent glomus tumors of fingertips: MR imaging evaluation. Radiology 2002;223(1):143-151 